\title{
BMJ
}

\section{Predicting which people with psychosocial distress are at risk of becoming dependent on state benefits: analysis of routinely available data}

\author{
Will Whittaker, research associate in health economics, ${ }^{1}$ Matt Sutton, professor of health economics, ${ }^{1}$ \\ Margaret Maxwell, professor of mental health, ${ }^{2}$ Rosalia Munoz-Arroyo, senior information analyst, ${ }^{3}$ \\ Sara MacDonald, research fellow, ${ }^{4}$ Andrew Power, medical prescribing adviser, ${ }^{5}$ Michael Smith, senior \\ research fellow, ${ }^{6}$ Philip Wilson, senior research fellow, ${ }^{4}$ Jill Morrison, professor of general practice ${ }^{4}$
}

${ }^{1}$ Health Sciences Research Group, School of Community Based Medicine, University of

Manchester, Jean McFarlane Building, Manchester M13 9PL

${ }^{2}$ Nursing, Midwifery and AHP Research Unit, University of Stirling, Stirling FK9 4LA

${ }^{3}$ Information Services Division, NHS National Services Scotland Area 122A, Edinburgh EH12 9EB

${ }^{4}$ Division of Community Based Sciences, Faculty of Medicine, University of Glasgow, Glasgow G12 9LX

${ }^{5}$ Pharmacy and Prescribing Support Unit, Queens Park House, Victoria Infirmary, Glasgow G42 9TT

${ }^{6}$ Department of Psychological Medicine, Division of Community Based Sciences, Gartnavel Royal Hospital, Glasgow G12 OXH

Correspondence to: J Morrison jmm4y@clinmed.gla.ac.uk

Cite this as: BMJ 2010;341:c3838 doi:10.1136/bmj.c3838

\section{ABSTRACT}

Objectives To examine whether there was significant variation in levels of claiming incapacity benefit across general practices. To establish whether it is possible to identify people with mental health problems who are more at risk of becoming dependent on state benefits for long term health problems based on their general practice consulting behaviour.

Design Interrogation of routinely available data in the Scottish Health Surveys and the British Household Panel Survey.

Setting Scotland and the United Kingdom.

Participants Respondents to the Scottish Health Surveys in 1995, 1998, and 2003 (7932, 12939 and 11472 respondents, respectively). Respondents to the British Household Panel Survey, 1991-2007 (more than 5000 households).

Main outcome measures Intracluster correlation coefficient for probability of work incapacity by general practice. Caseness according to the general health questionnaire (GHQ-12) and frequency of consultation with general practitioner in years before and after starting to claim incapacity benefit.

Results There was a small and non-significant amount of variation across general practices in Scotland in rate of claims for incapacity benefit after adjustment for other explanatory variables (intracluster correlation coefficient $0.01, P=0.135$ ). There was a significant increase in rates of GHQ-12 caseness from two years before the start of claiming incapacity benefit (odds ratio 1.6, 95\% confidence interval 1.3 to 1.9) and an increase in frequent consultation with a general practitioner from three years before the start of claiming incapacity benefit $(1.8,1.3$ to 2.4). People with GHQ-12 caseness showed a significant increase in frequent consultations with a general practitioner from two years before the start of claiming incapacity benefit (2.1, 1.4 to 3.2).

Conclusions There was no variation in levels of claiming incapacity benefit across general practices in Scotland after adjustment for differences in population characteristics and so initiatives targeted at practices with high levels are unlikely to be effective. People with mental health problems who are likely to have problems remaining in work can be identified up to three years before they transit on to long term benefits related to ill health.

\section{INTRODUCTION}

Increases in absences from work because of illness have been noted throughout western Europe and North America since the 1960s. ${ }^{1}$ In the United Kingdom the number of people claiming incapacity benefit and severe disablement allowance has increased by over $300 \%$ in the past 30 years, ${ }^{2}$ and the annual cost to the UK economy was estimated at over $£ 100 \mathrm{bn} .^{3}$ In 2007, the UK government made a commitment to reduce the number of just over 2.5 million people claiming incapacity benefit by one million as part of a wider aim of achieving an $80 \%$ national employment rate by $2016 .{ }^{24}$ As part of this drive, from October 2008 incapacity benefit, income support, and severe disablement allowance was replaced by the employment support allowance. ${ }^{5}$

In the UK, after one week of a patient's self certified sickness absence, general practitioners act as the immediate gateway to these benefits by issuing sickness certificates or "statements of incapacity for work" to patients when they are ill so that they can be absent from work without loss of income, until work capability assessments can be conducted within 13 weeks. ${ }^{6}$ Previous research has indicated that general practitioners' decisions about sickness certification might be inconsistent, resulting in considerable variation in the prevalence of claims for incapacity benefit across general practices. ${ }^{7}$

Over the past 10 years, claims for incapacity benefit remained stable at about $6.5 \%$ of the total British population, but over the same period the proportion of people claiming because of mental health problems increased from $32 \%$ to $45 \%{ }^{8}$ Some people with considerable mental health problems, nevertheless manage to remain in work with potentially positive 
Table 1| Random effects logistic regression models for work incapacity (data from Scottish Health Surveys). Figures are odds ratio $(95 \% \mathrm{Cl})$, unless stated otherwise

All individuals

Year (base: 1995):

\begin{tabular}{cl}
\hline 1998 & $0.99(0.87$ to 1.13$)$ \\
\hline 2003 & $0.84(0.72$ to 0.98$)$ \\
\hline Female & $0.66(0.59$ to 0.75$)$ \\
\hline
\end{tabular}

Age in years (base: age $\leq 25$ ):

\begin{tabular}{|c|c|}
\hline$>25-\leq 30$ & 2.1 (1.4 to 3.1$)$ \\
\hline$>30-\leq 35$ & $3.1(2.2$ to 4.4$)$ \\
\hline$>35-\leq 40$ & $4.2(2.97$ to 5.96$)$ \\
\hline$>40-\leq 45$ & $6.7(4.7$ to 9.4$)$ \\
\hline$>45-\leq 50$ & $8.9(6.4$ to 12.5$)$ \\
\hline$>50-\leq 55$ & 15.5 (11.1 to 21.6$)$ \\
\hline$>55-\leq 60$ & 20.6 (14.8 to 28.6$)$ \\
\hline$>60-\leq 65$ & 28.1 (19.6 to 40.5$)$ \\
\hline Minority ethnic group & 0.87 (0.44 to 1.7$)$ \\
\hline \multicolumn{2}{|l|}{ Marital status (base: single): } \\
\hline Married & $0.45(0.38$ to 0.53$)$ \\
\hline Separated & 0.85 (0.66 to 1.09$)$ \\
\hline Divorced & $1.04(0.85$ to 1.3$)$ \\
\hline Widowed & 0.67 (0.51 to 0.89$)$ \\
\hline Has a degree (base: no degree) & 0.50 (0.40 to 0.62$)$ \\
\hline \multicolumn{2}{|c|}{ Health board (base: Highlands and Islands): } \\
\hline Grampian and Tayside & $1.1(0.82$ to 1.4$)$ \\
\hline Lothian and Fife & $0.97(0.76$ to 1.2$)$ \\
\hline Borders, Dumfries, and Galloway & $0.90(0.67$ to 1.2$)$ \\
\hline Greater Glasgow & 1.4 (1.1 to 1.9$)$ \\
\hline Lanarkshire, Ayrshire, and Arran & 1.5 (1.1 to 1.8$)$ \\
\hline Forth Valley, Argyll, and Clyde & $1.2(0.88$ to 1.5$)$ \\
\hline Has mental illness & 5.5 (4.8 to 6.2$)$ \\
\hline \multicolumn{2}{|l|}{ Carstairs fifth (base: $1 \mathrm{st}=$ least deprived): } \\
\hline 2nd & 1.8 (1.4 to 2.2$)$ \\
\hline $3 r d$ & 2.3 (1.8 to 2.9$)$ \\
\hline 4th & 2.7 (2.1 to 3.4$)$ \\
\hline 5th (most deprived) & $4.0(3.2$ to 5.1$)$ \\
\hline Intracluster correlation coefficient $(r)^{*}$ & 0.01 (0.001 to 0.061$)$ \\
\hline Likelihood ratio test $r=0$ & $1.22(P=0.135)$ \\
\hline No of individuals & 18033 \\
\hline No of practices & 1002 \\
\hline
\end{tabular}

*Measures variation in work incapacity between practices.

benefits for their health, ${ }^{9}$ and it is not clear if those at increased risk of becoming dependent on benefits can be identified at an early stage so that additional support can be provided to help them remain in work.

We examined variation in levels of incapacity benefit at the level of general practice. We also investigated whether it is possible to identify people with mental health problems who are more at risk of becoming dependent on incapacity benefit based on their consulting behaviour in general practice.

\section{METHODS}

We used the Scottish Health Surveys (SHS) to examine variation in claims for incapacity benefit across general practices. ${ }^{10}$ We used the British Household Panel
Survey (BHPS) to examine changes over time in self reported mental health status, incapacity benefit claimant status, and frequency of consultations in general practice. ${ }^{11}$ We used the Scottish surveys because they can be linked to practice of registration and the British survey for the remaining analyses because it is longitudinal and allows us to observe individuals' histories of caseness and visits to a general practitioner before their claim for incapacity benefit.

\section{Analyses \\ Scottish Health Surveys}

To examine whether there are variations between practices in the rates at which populations are out of the labour market for health reasons, we used a random effects logistic regression model to estimate the intracluster correlation coefficient $(r)$. The intracluster correlation was estimated with Stata's xtlogit command $^{1415}$ and represents the proportion of total variance in work incapacity contributed by the variance component at practice level. ${ }^{16}$

Significant variation between practices might suggest that general practitioners make significantly different decisions about individual people taking time off work because of ill health. We estimated odds ratios to show the effects of each variable relative to a base category with estimates $>1$ presenting higher odds and those $<1$ representing lower odds.

We modelled the probability of being off work with ill health for the whole sample (including mental health problems as a binary variable) and then divided the sample into two groups: those with mental health problems and those without. We pursued this to investigate if there were differences in the factors that influenced the probabilities of being off work as a result of sickness and differences in the amount of variation among general practices between the two groups.

\section{British Household Panel Surveys}

To model changes in GHQ-12 caseness and consultations with a general practitioner, we identified respondents who claimed incapacity benefit at some point over the 17 waves of the surveys. We defined an episode of incapacity benefit as the period before transition on to, and during receipt of, incapacity benefit. Once an individual stops receiving incapacity benefit, a new episode begins. Among the individuals with at least one period on benefit, we modelled only the first observed episode. To ensure that we accurately measured time spent on benefit, we did not model those who were claiming benefit in the first wave. In such cases, we could not be sure how long an individual had been claiming before the survey.

With up to 17 years of data on each individual, we observed individuals a maximum of 16 years before the start of their first claim (if they started claiming for the first time in 2007) and a maximum of 15 years after the start of their first claim (if they started claiming for the first time in 1992 and continued claiming until 2007). We grouped observations longer than five 
Table $2 \mid$ Rates of GHQ caseness (score of $\geq 4$ ) over time during episode* of incapacity benefit (data from British Household Panel Survey)

Odds ratio compared with period $>5$ years before Year during episode No of observations Percentage rate $(95 \% \mathrm{Cl}) \quad$ claiming benefit $(95 \% \mathrm{Cl})$ Years before start of claiming incapacity benefit:

\begin{tabular}{lccc}
\hline$>5$ & 1727 & $26(24$ to 28$)$ & Reference \\
\hline 5 & 546 & $25(21$ to 29$)$ & $0.97(0.75$ to 1.3$)$ \\
\hline 4 & 724 & $28(25$ to 31$)$ & $1.2(0.93$ to 1.5$)$ \\
\hline 3 & 911 & $28(25$ to 31$)$ & $1.2(0.93$ to 1.5$)$ \\
\hline 2 & 1154 & $33(29$ to 35$)$ & $1.6(1.3$ to 1.9$)$ \\
\hline 1 & 1625 & $40(37$ to 42$)$ & $2.7(2.17$ to 3.2$)$ \\
\hline First year of claiming & 1665 & $47(45$ to 50$)$ & $4.1(3.4$ to 5.0$)$
\end{tabular}

incapacity benefit

Years after start of claiming incapacity benefit:

\begin{tabular}{llll}
\hline 1 & 719 & $46(42$ to 50$)$ & $3.3(2.6$ to 4.2$)$ \\
\hline 2 & 434 & $44(39$ to 49$)$ & $2.7(1.97$ to 3.6$)$ \\
\hline 3 & 305 & $45(40$ to 51$)$ & $2.7(1.9$ to 3.7$)$ \\
\hline 4 & 206 & $40(33$ to 47$)$ & $1.8(1.2$ to 2.6$)$ \\
\hline 5 & 144 & $40(32$ to 48$)$ & $1.7(1.1$ to 2.7$)$ \\
\hline 5 & 317 & $44(39$ to 50$)$ & $1.9(1.3$ to 2.8$)$ \\
\hline
\end{tabular}

*Includes years before starting to claim incapacity benefit and years spent claiming incapacity benefit. Episode ends when individual stops claiming. Individuals claiming when they first enter survey are excluded. Analysis includes only first episode for each individual.

years before entry on to incapacity benefit together and treated this as the reference category. To test for significant changes in rates of GHQ caseness and frequent consultations with a general practitioner over the period on incapacity benefit, we obtained confidence intervals using a random effects logistic regression on year dummies with clustering by respondent. The base category is the period greater than five years before entry on to incapacity benefit. The estimated odds ratios thus show the difference between each year and the period greater than five years before entry on to incapacity benefit.

Table $3 \mid$ Rates of frequent (\$10/year) consultations with general practitioner over time during episode of incapacity benefit (data from British Household Panel Survey)

Odds ratio compared with period $>5$ years before Year during episode No of observations Percentage rate $(95 \% \mathrm{Cl}) \quad \begin{gathered}\text { claiming benefit }(95 \% \mathrm{Cl}) \\ \text { claing }\end{gathered}$ Years before start of claiming incapacity benefit:

\begin{tabular}{|cccc}
\hline$>5$ & 1768 & $11(10$ to 13$)$ & Reference \\
\hline 5 & 559 & $11(9$ to 14$)$ & $1.1(0.74$ to 1.5$)$ \\
\hline 4 & 743 & $13(10$ to 15$)$ & $1.27(0.93$ to 1.75$)$ \\
\hline 3 & 935 & $16(14$ to 19$)$ & $1.79(1.3$ to 2.38$)$ \\
\hline 1 & 1198 & $18(16$ to 21$)$ & $2.3(1.78$ to 3.0$)$ \\
\hline First year of claiming & 1688 & $26(24$ to 28$)$ & $4.25(3.3$ to 5.4$)$ \\
\hline
\end{tabular}

incapacity benefit

Years after start of claiming incapacity benefit:

\begin{tabular}{cccc}
\hline 1 & 748 & $39(35$ to 42$)$ & $8.9(6.7$ to 11.8$)$ \\
\hline 2 & 448 & $34(29$ to 38$)$ & $5.7(4.1$ to 7.9$)$ \\
\hline 3 & 311 & $35(30$ to 41$)$ & $5.9(4.1$ to 8.6$)$ \\
\hline 4 & 210 & $36(30$ to 43$)$ & $6.3(4.2$ to 9.5$)$ \\
\hline 5 & 145 & $32(24$ to 40$)$ & $4.6(2.8$ to 7.4$)$ \\
\hline 5 & 322 & $28(23$ to 33$)$ & $2.9(1.9$ to 4.5$)$ \\
\hline
\end{tabular}

\section{RESULTS}

When we modelled the effect of being off work because of sickness in the Scottish surveys, without including other explanatory variables we found substantial and significant variation across general practices. For the whole sample the intracluster correlation coefficient $(r)$ was 0.086 . For those with mental health problems $r$ was 0.063 and for those without mental health problems $r$ was 0.059. All of these findings were significant at $\mathrm{P}<0.001$. When we controlled for other explanatory variables (table 1), however, we found a small and nonsignificant proportion of variation in the probability of work incapacity by practice $(r=0.01, \mathrm{P}=0.135)$. The intracluster coefficient remained small and non-significant when we carried out separate analyses in those with and those without mental health problems.

There were 1877 individuals in the British surveys who began a claim for incapacity benefit at least once over the 17 waves. There was a significant increase in rates of GHQ-12 caseness two years before a claim (odds ratio 1.6, 95\% confidence interval 1.3 to 1.9 ) (table 2). The odds of caseness rose, peaking in the first period of claiming, and then fell, settling at a significantly higher rate than the base in the long term. The risk of transiting on to incapacity benefit for those without GHQ-12 caseness was $0.98 \%$. Becoming a frequent visitor to a general practitioner increased the risk to $5 \%, 6 \%$, and $8 \%$ in years one, two, and three of being a frequent visitor, respectively. For those who had caseness and did not have frequent visits, the risk was $1.2 \%$. Having caseness and becoming a frequent visitor increased the risks of transiting on to incapacity benefit to $6 \%, 13 \%$, and $16 \%$ in years one, two, and three, respectively.

A significant increase in the prevalence of frequent consultations with a general practitioner was evident from three years before the first claim for incapacity benefit (1.8, 1.3 to 2.4) (table 3). As for GHQ caseness, the rates peaked in the first period of claiming and then fell but remained over twice as high as in the period more than five years before starting incapacity benefit. When we restricted the analysis to those with GHQ caseness, rates of frequent consultations with a general practitioner followed a similar pattern (table 4), though the increase in rates in the period before claiming incapacity benefit was significant only from two years before starting to claim benefit.

For all three models, the proportion of variation in GHQ caseness/frequent consultations with a general practitioner explained by the individual level variance component was significant and large $(r=0.46$ ( 0.43 to $0.50)$ for GHQ caseness; 0.48 (0.44 to 0.51$)$ for frequent consultations; and 0.44 (0.38 to 0.50$)$ for frequent consultations for those with GHQ caseness).

\section{DISCUSSION}

\section{Main findings}

We found no significant variation across general practices in Scotland in rates of claiming incapacity benefit once we controlled for differences in population 
Table $4 \mid$ Rates of frequent (\$10/year) consultations with general practitioner over time during episode of incapacity benefit for those with GHQ caseness (score $\geq 4$ )

Odds ratio compared with period $>5$ years before Year during episode No of observations Percentage rate $(95 \% \mathrm{Cl}) \quad$ claiming benefit $(95 \% \mathrm{Cl})$ Years before start of claiming incapacity benefit:

\begin{tabular}{|cccc}
\hline 5 & 449 & $20(16$ to 24$)$ & Reference \\
\hline 5 & 136 & $24(17$ to 32$)$ & $1.3(0.74$ to 2.3$)$ \\
\hline 4 & 202 & $21(15$ to 27$)$ & $0.99(0.59$ to 1.7$)$ \\
\hline 3 & 251 & $25(20$ to 31$)$ & $1.4(0.85$ to 2.2$)$ \\
\hline 1 & 367 & $30(25$ to 35$)$ & $2.1(1.4$ to 3.2$)$ \\
\hline First year of claiming & 643 & $38(34$ to 42$)$ & $3.2(2.2$ to 4.6$)$ \\
\hline
\end{tabular}

incapacity benefit

Years after start of claiming incapacity benefit:

\begin{tabular}{cccc}
\hline 1 & 329 & $52(46$ to 57$)$ & $6.9(4.5$ to 10.7$)$ \\
\hline 2 & 190 & $44(37$ to 51$)$ & $3.7(2.3$ to 6.1$)$ \\
\hline 3 & 138 & $48(39$ to 57$)$ & $5.1(2.96$ to 8.8$)$ \\
\hline 4 & 82 & $45(34$ to 57$)$ & $5.1(2.6$ to 9.8$)$ \\
\hline 5 & 57 & $49(36$ to 63$)$ & $5.4(2.6$ to 11.5$)$ \\
\hline 5 & 141 & $31(24$ to 40$)$ & $1.8(0.97$ to 3.3$)$ \\
\hline
\end{tabular}

characteristics. This suggests that variations in rates of claiming across general practices are caused by population differences rather than differences in general practitioners' behaviour regarding sickness certification.

People who started claiming incapacity benefit were more likely to show GHQ-12 caseness from two years before their first claim and to consult frequently from three years before their first claim. Once on incapacity benefit, rates of GHQ-12 caseness and frequent consultation remained higher than the rates observed over the five years before the transition.

\section{Strengths and weaknesses}

Other studies have looked at frequent consultation in general practice and receipt of incapacity benefit, but these have tended to be studies in single practices or groups of practices in a defined area. We looked at this issue across 17 waves of the British Household Panel Survey, which is a representative sample of the whole population and the findings are, therefore, likely to be more robust.

We used a cut off of 10 or more consultations to describe frequent consulters because this was the highest level used in the British surveys. A systematic review of frequent consultations found that most studies used a cut off of 9-14 consultations a year to define frequent consulters. ${ }^{17} \mathrm{~A}$ recent study showed that the way in which frequent attendance is defined has an impact on the factors associated with it and their discriminative power. The authors recommended use of a top decile cut off for defining frequent attendance. ${ }^{18}$

The Scottish and British surveys both use the GHQ12 as a measure of psychosocial distress. This measure gives an indication of potential mental health problems, rather than providing a definite diagnosis.

We modelled only one episode of being in receipt of incapacity benefit per individual, and this had to have started during the sample period. We excluded anyone already claiming incapacity benefit before 1991. Inclusion of 17 waves of the British surveys, however, still gives a large sample of new claimants and substantial periods before and after the start of claiming incapacity benefit for these new claimants.

The panel nature of the British surveys enabled us to control for potential bias caused by individual heterogeneity - that is, unexplained variations in rates of the dependent variable between individuals. We found this to be significant in each of the models.

We did not know the main cause of transition on to incapacity benefit; it might have been caused by another condition, such as a physical illness, and the increase in "caseness" before entry could, therefore, be a symptom of another condition. Nevertheless, the key finding that it might be possible to identify those people most likely to transit on to incapacity benefit according to GHQ-12 caseness and frequent consultation behaviour still holds.

\section{Comparison with previous research}

In a 2004 letter in the $B M J$, Hardy claimed that general practitioners issue certificates unthinkingly, inconsistently, and irresponsibly. ${ }^{19}$ Roope et al pointed out that "we do not know the true variability of sickness certification," although later in the same paper these authors stated that "sickness absence certification is poorly administered and as a result hugely variable." 20 There seems to be confusion about the extent of variation in issuing sickness certification, and there is little research evidence that identifies the size and nature of any variation. Our study indicates that, even if there is huge variability among general practitioners in issuing sickness certificates, there was no significant variation between general practices in levels of incapacity benefit claimants once population differences were taken into account. This suggests that the behaviour of individual general practitioners was not a large factor in determining whether someone transits on to incapacity benefit.

Though other studies have also shown a relation between long term incapacity for work, mental health problems, and frequent consultation in general practice, none has shown that frequent consultation is predictive up to three years before the start of claiming incapacity benefit. In a comprehensive quantitative study of sickness certification in general practice, mild mental disorders accounted for $40 \%$ of sickness absence and these disorders were particularly associated with claimants developing longer term sickness absence. ${ }^{21}$ The reason for sickness absence was changed relatively infrequently on continuing absences within the same episode, and the authors stated that relatively few of these long term claimants ever return to paid work. A Finnish study of frequent consulters in primary care found that these patients were a high risk group for long term sickness leave. ${ }^{22}$ The most common disorders were anxiety and depression. In a UK study, $47 \%$ of chronic frequent consulters had a mental 


\section{WHAT IS ALREADY KNOWN ON THIS TOPIC}

Illness related absence from work is a costly problem that governments are seeking to reduce

Mild mental disorders and frequent consultations in general practice are associated with long term sickness absence

Sickness certification behaviour might vary between general practitioners

\section{WHAT THIS STUDY ADDS}

There was no variation in levels of claiming incapacity benefit across general practices in Scotland after adjustment for differences in population characteristics

Mild mental health disorders and frequent consultation behaviour can predict long term sickness absence up to three years before people start to claim benefit

health problem compared with $2 \%$ of control patients. ${ }^{23}$ A systematic review including studies from Europe, North America, and Australasia found that frequent consultation was associated with an excess of psychiatric symptoms - up to $50 \%$ of frequent consulters had emotional distress-but they did not see themselves as psychiatrically unwell. ${ }^{17}$ Around a third of people continued to consult frequently during a two year follow-up period, and persistence was associated with psychoneurotic problems. ${ }^{17}$ Occupational difficulties were over-represented among frequent consulters. ${ }^{17}$

\section{Implications for policy and practice}

If general practitioners were issuing sickness certificates inappropriately, we would expect that some practices would have higher than expected rates of incapacity benefit claimants. Our research, however, showed no evidence that this was the case. Initiatives targeted at individual general practices and aimed at keeping people with mental health problems in work because more patients than expected transit on to long term benefit in these practices might, therefore, not be effective. The lack of significant variation across general practices in Scotland in rates of claiming incapacity benefit reinforces our view that general practitioners could be part of the solution to the problem of prolonged incapacity for work and the associated health and social difficulties that this brings, rather than contributing to the problem.

Much current policy is aimed at getting people who are on long term benefit back to work. It might, however, be more effective to focus on keeping those vulnerable to becoming dependent on benefit in work, rather than getting them back into work after a long period of absence from the workplace. General practitioners are well placed to identify people who are vulnerable to becoming dependent on benefit up to three years before this occurs by identifying frequent consulters with emotional distress. Once such people are identified, however, it is not clear what general practitioners can do to maintain these patients in work, if that is the most appropriate outcome for individual patients. Further work should concentrate on determining what outcomes are achieved by general practitioners who provide additional emotional or occupational support for patients identified as at risk of becoming dependent on long term benefits. More fundamental research is also required to find out whether recent initiatives involving general practitioners, such as the introduction of "Fit Notes," can have an effect on this high risk group. ${ }^{24}$

Contributors: WW undertook the detailed analyses, provided a report on which this paper was based, and contributed to writing the paper. MS is a grant holder and member of the steering group for this study; he supervised the analyses and contributed to writing this paper. MM, RM-A, SMacD, AP, MS, and PW are grant holders and members of the steering group for this study and contributed to discussions of the results and writing the paper. JM is the principal investigator and wrote the grant for this study, drafted the paper and coordinated the writing of the final version, and is guarantor.

Funding: This study was funded by the Chief Scientist Office of the Scottish Government (No CZH/4/400).

Competing interests: All authors have completed the Unified Competing Interest form at www.icmje.org/coi_disclosure.pdf (available on request from the corresponding author) and declare: no support from any institution for the submitted work; no financial relationships with any institutions that might have an interest in the submitted work in the previous 3 years; no other relationships or activities that could appear to have influenced the submitted work.

Ethical approval: This study was approved by the West of Scotland multicentre ethics committee 1 (No 07/S0703/58). This study involved analysis of routine, publicly available data and individual patient consent was not required. Both the Scottish Health Surveys and British Household Panel Surveys obtain individual participant informed consent. Data sharing: The data used in this study are all in the public domain.

1 Moncrieff J, Pomerleau J. Trends in sickness benefits in Great Britain and the contribution of mental disorders. I Public Health Med 2000;22:59-67.

2 Freud, D. Reducing dependency, increasing opportunity: options for the future of Welfare to Work. Department for Work and Pensions, 2007.

3 Black DC. Working for a healthier tomorrow. 2008. www. workingforhealth.gov.uk/documents/working-for-a-healthiertomorrow-tagged.pdf.

4 Anyadike-Danes M, McVicar D. Has the boom in incapacity benefit claimant numbers passed its peak? Fisc Stud 2008;29:415-34.

5 Department of Work and Pensions. Employment support allowance. 2009. www.dwp.gov.uk/employment-and-support/.

6 Department for Social Development. Healthcare professionals. 2009. www.dsdni.gov.uk/index/ssa/benefit_information/ssaniesa/esa-healthcare-professionals.htm.

7 Hussey S, Hoddinott P, Wilson P, Dowell I, Barbour R. Sickness certification system in the United Kingdom: a qualitative study of views of general practitioners in Scotland. BMJ 2004;328:88-90.

8 McVicar D, Anyadike-Danes M. Panel estimates of the determinant of British regional male incapacity benefit rolls 1998-2006. Appl Econ 2008;40:1-15.

9 Waddell G, Burton AK. Is work good for your health and wellbeing? Stationery Office, 2006.

10 Scottish Government. Scottish health survey. 2009. www.scotland. gov.uk/Topics/Statistics/Browse/Health/scottish-health-survey.

11 Taylor MR, ed, with Brice J, Buck N, Prentice-Lane E. British household panel survey user manual. Vol A. Introduction, technical report and appendices. University of Essex, 2001.

12 Goldberg DP, Gater R, Sartorius N, Ustun, TB, Piccinelli M, Gureje O, et al. The validity of two versions of the GHQ in the WHO study of mental illness in general health care. Psychol Med 1997;27:191-7.

13 Carstairs V, Morris R. Deprivation and health in Scotland. Aberdeen University Press, 1991.

14 Statacorp. Longitudinal/panel data reference manual release 10. Statacorp, 2008.

15 Skrondal A, Rabe-Hesketh S. Generalized latent variable modelling multilevel, longitudinal, and structural equation models. Chapman and Hall/CRC, 2004.

16 Bland JM, Altman DG. Measurement error and correlation coefficients. BMJ 1996;313:41-2. 
17 Gill D, Sharpe M. Frequent attenders in general practice: a systematic review of studies of prevalence, associations and outcome. I Psychosom Res 1999;47:115-30.

18 Luciano JV, Fernanadez A, Pinto-Meza A, Lujan L, Bellon JA, Garcia-Campayo J, et al. Frequent attendance in primary care comparison and implications of different definitions. Br J Gen Pract 2010;60:49-55.

19 Hardy JN. Sickness certification system in the United Kingdom: doctors are indeed agents of social control. BMJ 2004;328:461.

20 Roope R, Parker G, Turner S. General practitioners' use of sickness certificates. Occup Med 2009;59:580-5.
21 Shiels C, Gabbay MB, Ford FM. Patient factors associated with duration of certified sickness absence and transition to long-term capacity. Br J Gen Pract 2004; 54:86-91.

22 Karlsson H, Lehtinen V, Joukamaa M. Psychiatric morbidity among frequent attender patients in primary care. Gen Hosp Psychiatry 1995;17:19-25.

23 Heywood PL, Cameron Blackie G, Cameron IH, Dowell AC. An assessment of the attributes of frequent attenders to general practice. Fam Pract 1998;15:198-204.

24 Directgov. Statement of fitness for work (fit note). 2010. www.direct. gov.uk/en/Nl1/Newsroom/DG_184645. 